\title{
Awareness of Obstetric Vesicovaginal Fistula among Pregnant Women in a Rural Hospital
}

\author{
P. O. Ezeonu1, K. C. Ekwedigwe1, M. E. Isikhuemen'2*, M. O. Eliboh ${ }^{3}$, R. C. Onoh'1, L. O. Lawani1, \\ L. O. Ajah', E. I. Dimejesi ${ }^{1}$ \\ ${ }^{1}$ Department of Obstetrics and Gynecology, Federal Teaching Hospital, Abakaliki, Nigeria \\ ${ }^{2}$ Department of Obstetrics and Gynaecology, University of Benin Teaching Hospital, Benin City, Edo State, Nigeria \\ ${ }^{3}$ National Obstetric Fistula Centre, Abakaliki, Nigeria \\ Email: maradona4real2002@yahoo.com
}

How to cite this paper: Ezeonu, P.O., Ekwedigwe, K.C., Isikhuemen, M.E., Eliboh, M.O., Onoh, R.C., Lawani, L.O., Ajah, L.O. and Dimejesi, E.I. (2017) Awareness of Obstetric Vesicovaginal Fistula among Pregnant Women in a Rural Hospital. Advances in Reproductive Sciences, 5, 39-46. https://doi.org/10.4236/arsci.2017.53005

Received: July 18, 2017

Accepted: August 19, 2017

Published: August 22, 2017

Copyright $\odot 2017$ by authors and Scientific Research Publishing Inc. This work is licensed under the Creative Commons Attribution International License (CC BY 4.0).

http://creativecommons.org/licenses/by/4.0/

(c) (i) Open Access

\begin{abstract}
Background: Giving birth should be a period of joy, but for more than half a million women, their pregnancy and childbirth end in death while some develop vesicovaginal fistula. Vesicovaginal fistula is an abnormal communication between the bladder and the vagina leading to continuous leakage of urine through the vagina. Little is known about the perception of pregnant women about obstetric fistula and this group of women are those who are at risk of the disease. Our aim therefore was to evaluate the level of awareness of vesicovaginal fistula among pregnant women attending antenatal clinic in a rural hospital. Methodology: This was a cross sectional study conducted at Mile 4 missionary Hospital, Abakaliki, between 1st of May and 1st of July, 2017. Data was collected with the use of questionnaire. Ethical clearance was gotten from the institutions ethical committee. Results: Their mean age was $27 \pm 5$ years and mean parity was $2 \pm 2$. Awareness of vesicovaginal fistula was $57.8 \%$. Risk factors identified for vesicovaginal fistula were prolonged obstructed labour, instrumental vaginal delivery, caesarean section and short stature. Only 80 (39.2\%) believed vesicovaginal fistula could be treated. Conclusion: Awareness of vesicovaginal fistula in the study population was $57.8 \%$. A significant number of women were not aware that vesicovaginal fistula could be treated.
\end{abstract}

\section{Keywords}

Vesicovaginal Fistula, Awareness, Pregnancy, Prolonged Obstructed Labour 


\section{Introduction}

Giving birth should be a time of joy, but for more than half a million women, their pregnancy and childbirth end in death and for every woman who dies, 20 to 50 women suffer serious injuries and disabilities, including obstetric fistula [1]. Vesicovaginal fistula is an abnormal communication between the bladder and the vagina leading to continuous leakage of urine through the vagina [2]. A lot has been documented about management of patients with obstetric fistula but little is known about its perception among pregnant women. If a woman does not get pregnant, she will not develop obstetric fistula hence this group of women require adequate information about obstetric fistula. The prevalence of fistula in developing countries is high, most of which are obstetric-related [3].

Our antenatal clinics usually focus on immunization, breastfeeding, nutrition and other reproductive health issues but little emphasis is placed on vesicovaginal fistula. If pregnant women are aware of the risk factors of vesicovaginal fistula and the psychosocial morbidities associated with the disease, they would probably start requesting for emergency caesarean section/referral to better health facilities when they perceive that their labour is becoming longer than expected.

Obstetric fistula destroys the life of many young women in developing countries but this is not so for the industrialized world [3]. It usually develops from prolonged obstructed labour that occurs as a result of fetopelvic disproportion during the course of delivery. Iatrogenic injury also plays an important role in obstetric fistula formation. Other risk factors for obstetric fistula are poor socioeconomic status, poor nutrition, early marriage, lack of access to quality health care/ emergency caesarean section, unskilled birth attendants, poor utilization of family planning methods among other factors.

Previous studies have shown poor knowledge about obstetric vesicovaginal fistula and its causes [4] [5]. In a study done in northern Nigeria [6], most healthy females believed that obstetric vesicovaginal fistula was a punishment from the gods to the affected person for their infidelity while the majority of women with obstetric fistula in that study believed that their condition either resulted from the effect of a poison from the skull bone of their dead macerated foetus or from manipulations by the traditional birth attendant while trying to deliver the dead foetus.

Obstetric fistula is considered to be the most devastating morbidity that affects women following childbirth. Medical consequences of fistula include incontinence, infection and possibly infertility. Social consequences of fistula are isolation, abandonment, stigma and vulnerability [1].

This study will add to the current body of knowledge relating to obstetric vesicovaginal fistula. It will also serve as a reference material for future research.

The aim of this study was to evaluate the level of awareness of vesicovaginal fistula among pregnant women in a rural hospital. 


\section{Methodology}

\subsection{Study Area}

The study was conducted at Mile 4 hospital, Abakaliki, Ebonyi State. Mile 4 hospital is a missionary hospital which provides care mainly to pregnant women and children. Ebonyi state is primarily an agricultural region.

\subsection{Study Population}

Study population comprised of women presenting for antenatal clinic visit.

\subsection{Inclusion Criteria}

Pregnant women who presented for routine antenatal care.

\subsection{Exclusion Criteria}

Pregnant women who did not give consent.

\subsection{Study Design}

Cross-sectional.

\subsection{Ethical Consideration}

Permission for this study was obtained from the Ethical Committee of Mile 4 hospital. Voluntary informed consent was obtained from participants.

\subsection{Sample Size Determination}

The formula below was used to calculate the sample size.

$$
\mathrm{n}=\frac{\mathrm{Z}^{2} \mathrm{pq}}{\mathrm{d}^{2}}
$$

where $\mathrm{n}=$ minimum sample size

$\mathrm{Z}=$ standard normal deviation or $\mathrm{Z}$-score $=1.96$

$\mathrm{p}=$ prevalence of respondents who had high knowledge of vesicovaginal fistula in a study done in Kebbi, Nigeria (4.7\%) [4].

$$
\begin{aligned}
& \mathrm{Q}=1-\mathrm{p} \\
& \mathrm{d}=\text { level of accuracy }=0.05 \\
& \mathrm{n}=\frac{(1.96)^{2} \times 0.047 \times 0.953}{(0.05)^{2}} \\
& \mathrm{n}=69 .
\end{aligned}
$$

However 204 respondents were involved in this study.

\subsection{Study Duration}

This study was conducted between 1st of May and 1st of July 2017. 


\section{Method of Sampling}

Convinient sampling method.

\subsection{Method of Data Collection}

Data collection was with the aid of semi-structured questionnaires containing open and close ended questions on socio-demographic data, awareness of risk factors for obstetric vesicovaginal fistula, awareness of complications of obstetric vesicovaginal fistula and knowledge about its prevention.

\subsection{Data Analysis}

Data from questionnaire was collated and entered into a spread sheet for analysis using the Statistical Package for Social Sciences (SPSS) Version 21.

\section{Results}

The mean age was $27 \pm 5$, and the mean parity was $2 \pm 2$. Most of them were in the reproductive age group as shown in Table 1. Majority (99\%) were Christians.

A hundred and eighteen (57.8\%) had knowledge about vesicovaginal fistula while $86(42.2 \%)$ do not appear to have knowledge about the disease. Only 51 (25\%) knew that pregnant women were at risk of vesicovaginal fistula. The risk factors for vesicovaginal fistula identified by the respondents were prolonged labour, instrumental vaginal delivery, caesarean section and short stature (Table 2). Seven (3.4\%) women believe that vesicovaginal fistula was punishment from the gods.

A hundred and seventy three $(84.8 \%)$ of the pregnant women were ready to deliver their babies in the hospital and $74(36.3 \%)$ identified delivery in the place of a traditional birth attendant as a risk factor for vesicovaginal fistula.

The negative effects of vesicovaginal fistula identified by the respondents were marital disharmony in 76 (37.3\%), depression in 96 (47.1\%), and infertility in 48 (23.5\%). Eighty respondents (39.2\%) were aware that vesicovaginal fistula can be treated and $39.2 \%$ believed it is preventable.

\section{Discussion}

Vesicovaginal fistula has continued to remain a source of worry in developing countries. There is need to assess the level of awareness about this disease condition which could be a positive step in the reduction of obstetric fistula.

In this study, awareness of vesicovaginal fistula was $57.8 \%$. This shows that despite the problems associated with obstetric fistula, many women are not aware of the disease entity. It may be difficult to control a disease that people are not aware of. This finding may also imply that these women will not be aware of how to prevent obstetric fistula. If such women develop obstetric fistula during the process of childbirth, it will also become difficult for them to get treatment since they may not even be aware that it can be treated. In a study conducted in 
Table 1. Sociodemographic variables of the respondents.

\begin{tabular}{|c|c|}
\hline Variable & Frequency $(\%)$ \\
\hline \multicolumn{2}{|l|}{ Age } \\
\hline$<15$ & $2(1)$ \\
\hline $15-19$ & $6(2.9)$ \\
\hline $20-24$ & $53(26)$ \\
\hline $25-29$ & $83(40.7)$ \\
\hline $30-34$ & $41(20.1)$ \\
\hline $35-39$ & $16(7.8)$ \\
\hline $40-44$ & $3(1.5)$ \\
\hline \multicolumn{2}{|l|}{ Tribe } \\
\hline Igbo & $203(99.5)$ \\
\hline Yoruba & $1(0.5)$ \\
\hline \multicolumn{2}{|l|}{ Religion } \\
\hline Christian & $202(99)$ \\
\hline Islam & $1(0.5)$ \\
\hline African Traditional Religion & $1(0.5)$ \\
\hline \multicolumn{2}{|l|}{ Occupation } \\
\hline Trading & $69(33.8)$ \\
\hline Farming & $34(16.7)$ \\
\hline Teaching & $17(8.3)$ \\
\hline Students & $84(41.2)$ \\
\hline \multicolumn{2}{|l|}{ Level of Education } \\
\hline Primary & $99(48.5)$ \\
\hline Secondary & $44(21.6)$ \\
\hline Tertiary & $17(8.3)$ \\
\hline No Formal Education & $44(21.6)$ \\
\hline \multicolumn{2}{|l|}{ Marital Status } \\
\hline Married & $191(93.6)$ \\
\hline Single & $12(5.9)$ \\
\hline Divorced & $1(0.5)$ \\
\hline \multicolumn{2}{|l|}{ Parity } \\
\hline Nullipara & $71(34.8)$ \\
\hline Primipara & $36(17.6)$ \\
\hline Multipara & $82(40.2)$ \\
\hline Grandmultipara & $15(7.4)$ \\
\hline
\end{tabular}


Table 2. Risk factors for vesicovaginal fistula identified by the respondents.

\begin{tabular}{cc}
\hline Risk factor & Frequency (\%) \\
\hline Prolonged labour & $108(52.9)$ \\
Instrumental vaginal delivery & $57(27.9)$ \\
Caesarean section & $26(12.7)$ \\
Short stature & $13(6.4)$ \\
\hline
\end{tabular}

Burkina Faso among young women, 36.4\% of respondents were aware of obstetric fistula [7]. Our study however showed a higher level of awareness. The reason may be because of the functional fistula centre which is close to the study area. These women may have also had information about obstetric fistula during their antenatal visit.

Only $25 \%$ of respondents correctly identified that pregnant women are mostly at risk of vesicovaginal fistula. In developing countries, vesicovaginal fistula remains obstetric related [8]. It is therefore worrisome that despite the fact that about half of these women have heard of vesicovaginal fistula, only a quarter think being pregnancy places a woman at risk of this disease. If they are not aware that they are at risk of developing this disease, it means they may not be able to take practical steps in its prevention. In antenatal clinics, it should be clearly stated to women that vesicovaginal fistula in developing countries is largely obstetric related.

Only $52.9 \%$ correctly identified prolonged obstructed labour as a risk factor for the formation of obstetric vesicovaginal fistula. Prolonged obstructed labour remains the major risk factor for obstetric fistula in developing countries [8]. In such circumstances, maternal soft tissues are trapped between the presenting part and the maternal pubic bone or sacrum. This subsequently results in ischemia and necrosis resulting in leakage of urine or faeces through the vagina. In a study conducted in Sokoto, Nigeria $70 \%$ of women with genital fistula identified prolonged labour as the cause of their fistula [9]. This may have differed from our study because the women in that study had genital fistula and have already been admitted into the hospital which may have influenced their knowledge about the disease.

Thirteen (6.4\%) women identified short stature as a risk factor for vesicovaginal fistula. It has previously been demonstrated that maternal height is a good determinant of labour outcome as short women are more likely to have cephalopelvic disproportion and subsequently obstructed labour [10] [11]. This is an important risk factor for the formation of vesicovaginal fistula. If short women know that their pregnancy is a high risk, it will make them to deliver in health institutions that have facilities for quality obstetric care including caesarean section when indicated.

Despite the level of information and knowledge that is currently available with regards to vesicovaginal fistula, $37.3 \%$ believed it is a punishment from the gods. 
This shows that in our society some people are still ignorant. Women with such belief are not likely to seek proper medical care if they are affected neither will they persuade any of their affected relative to seek good medical care. Hence proper counselling needs to be done as this will help in the eradication of obstetric fistula.

This study has some limitations. It was a hospital based study hence its result may be difficult to generalise. Also a larger sample size would be better for this study.

We recommend that antenatal sections should expose women to the causes of obstetric vesicovaginal fistula, its methods of prevention and treatment.

\section{Conclusion}

Obstetric fistula is a source of worry to medical practitioners in developing countries. Knowledge about it and the risk factors appear inadequate. There is need to properly inform women during their antenatal clinic visits about the risk factors for obstetric fistula and where to find care when faced with this challenge.

\section{References}

[1] John Hopkins Bloomberg School of Public Health (2005) Prevention and Treatment of Obstetric Fistula: Identifying Research Needs and Public Health Priorities. John Hopkins Bloomberg School of Public Health, Baltimore. https://www.jhsph.edu

[2] Ekwedigwe, K., Sunday-Adeoye, I., Isikhuemen, E., Daniyan, B. and Yakubu, E. (2017) Spontaneous Vesicovaginal Fistula in Neurofibromatosis: A Case Report. Gynecology \& Obstetrics (Sunnyvale), 7,421. https://doi.org/10.4172/2161-0932.1000421

[3] De Ridder, D., Badlani, G.H., Browning, A., et al. (2009) Committee 18. Fistulas in the Developing World.

[4] Amna, A., Sirichand, P. and Nadeem, F. (2005) Women Perception and Awareness about Genitourinary Fistula. Journal of Liaquat University of Medical and Health Sciences, 14, 129-132.

[5] Basheer, S. and Pumpaibool, T. (2015) Knowledge, Attitude and Mental Health Care Utilization among Married Women of Reproductive Age towards Vesicovaginal Fistula in Kebbi State, Nigeria. Journal of Health Research, 29, 93-100.

[6] Umoiyoho, A.J. and Inyang, E.C. (2012) Community Misconception about the Aetiopathogenesis and Treatment of Vesicovaginal Fistula in Northern Nigeria. International Journal of Medicine and Biomedical Research, 1, 193-198. https://doi.org/10.14194/ijmbr.136

[7] Banke-Thamas, A.O., Kouraogo, S.F., Siribie, A., Taddese, H.B. and Mueller, J.E. (2013) Knowledge of Obstetric Fistula Prevention among Young Women in Urban and Rural Burkina Faso: A Cross-Sectional Study. PLoS One, 8, e85921. https://doi.org/10.1371/journal.pone.0085921

[8] Wall, L.L., Karshima, J.A., Kirschner, C. and Arrowsmith, S.D. (2004) The Obstetric Vesicovaginal Fistula: Characteristics of 899 Patients from Jos, Nigeria. The Journal of Obstetrics and Gynecology, 190, 1011-1019.

[9] Hassan, M.A. and Ekele, B.A. (2009) Vesicovaginal Fistula: Do the Patients Know the Cause? Annals of African Medicine, 8, 122-126. 
https://doi.org/10.4103/1596-3519.56241

[10] Toh-adam, R., Srisupundit, K. and Tongsong, T. (2012) Short Stature as an Independent Risk Factor for Cephalopelvic Disproportion in a Country of Relatively Small-Sized Mothers. Archives of Gynecology and Obstetrics, 285, 1513-1516. https://doi.org/10.1007/s00404-011-2168-3

[11] Tsu, V.D. (1992) Maternal Height and Age: Risk Factors for Cephalopelvic Disproportion in Zimbabwe. International Journal of Epidemiology, 21, 941-946.

https://doi.org/10.1093/ije/21.5.941

Submit or recommend next manuscript to SCIRP and we will provide best service for you:

Accepting pre-submission inquiries through Email, Facebook, LinkedIn, Twitter, etc. A wide selection of journals (inclusive of 9 subjects, more than 200 journals)

Providing 24-hour high-quality service

User-friendly online submission system

Fair and swift peer-review system

Efficient typesetting and proofreading procedure

Display of the result of downloads and visits, as well as the number of cited articles Maximum dissemination of your research work

Submit your manuscript at: http://papersubmission.scirp.org/

Or contact arsci@scirp.org 